\title{
PCR-RFLP ITS-based analysis of wine yeast autochthonous strains isolated from different grape cultivars in Taman subregion
}

\author{
Elena Lobodina*, Ivan Suprun, Natalya Ageeva, and Ekaterina Al-Nakib \\ North Caucasian Federal Scientific Center of Horticulture, Viticulture, Wine-making, Krasnodar, \\ Russia
}

\begin{abstract}
The studies present the results of morphological, cultural and genetic analysis of the ITS1-ITS4 region of the autochthonous yeast strains genome by using the HaeIII restriction enzyme. On the red and white grapes varieties, based on the morphology of the cells, autochthonous strains belonging to the genus Saccharomyces prevail $-83.3 \%$, what is confirmed by genetic analysis of rDNA ITS region. Restriction analysis showed that all strains of the genus Saccharomyces belong to the species Saccharomyces cerevisiae / S. paradoxus. The percentage of Saccharomyces isolated on the Pervenets Magaracha variety is $86.7 \%$, Krasnostop Anapsky - 80\%. The non-Saccharomyces yeast had a product size of $750 \mathrm{bp}$, presumably of the species Hanseniaspora uvarum.
\end{abstract}

\section{Introduction}

Winemaking in Russian industry is really important. At present, the Krasnodar Territory is the leader among the wine-growing regions of the Russian Federation, whose vineyards area is about 25.5 thousand hectares (30\% of all vineyards in the country), the share of harvested grapes is $40 \%$ [1]. Recently, the production of wines of the "terroir" type is of particular relevance, the organoleptic properties of which are contributed not only by the grape variety and agroclimatic conditions, but also by specific, autochthonous strains of wine yeast. These strains are usually associated with specific characteristics that determine the properties of wines, in connection with which the wine acquires individuality [2].

Only by using the yeasts, which are well-studied and tested with known technological properties strains of the genus Saccharomyces, can guarantee the production of wine with the desired properties. [3, 4]. The search for new strains promising for winemaking is relevant and carried out by many scientists [5-9].

The use of specialized yeast during the grapes fermentation makes it possible to obtain high-quality wines. In this regard, the search for promising autochthonous strains is relevant for the development of the wine industry in Russia and for production of high quality wines. One of the most important and topical directions in the search for these yeast strains is types

\footnotetext{
* Corresponding author: alyona2255@yandex.ru
} 
identification, because not all strains are suitable for winemaking, and some of them can lead to wine spoilage.

\section{Materials and methods}

Objects of research: monocultures of yeast isolated from the surface of the grapes varieties Krasnostop Anapsky (clone of the variety Krasnostop Zolotovsky) and Pervenets Magaracha (Rkatsiteli ${ }^{\times}$Magarach 124-66-39), isolated in the vineyards of the Temryuk region of the Krasnodar Territory in the amount of 60 pieces.

Materials and research methods: sampling was carried out in dry weather during the period of berries technical ripeness. Grape samples (bunches) weighing about $2 \mathrm{~kg}$ were placed in sterile bags and transported to the laboratory. Then, under aseptic conditions, the grapes were crushed and the resulting filtered wort was placed in a sterile dish with a cotton-gauze stopper and fermented at a temperature of $23-25^{\circ} \mathrm{C}$. When $70 \mathrm{~g} / \mathrm{dm}^{3}$ of sugar was fermented, the inoculation was carried out by the depleting streak method into Petri dishes on a solid nutrient medium of the following composition: yeast extract - $1 \% \mathrm{w} / \mathrm{v}$, peptone - $2 \% \mathrm{w} / \mathrm{v}$, glucose $-1 \% \mathrm{w} / \mathrm{v}$. From colonies grown on a dense environment, pure cultures were taken. The morphological and cultural properties were assessed a month after sowing monocultures (Microscope Olympus, Japan) according to the recommendations [10, 11]. DNA extraction, conditions for PCR and gel electrophoresis were performed according to the recommendations [12].

\section{Results and discussion}

It is known that yeast colonies, depending on the species, can have various shapes: round, with or without septa, radial or feathery, with the formation of a clearly defined inner ring [13]. The surface of the colony can be shiny and dull, dry and wet, smooth and wrinkled, with smooth or deformed edges. In addition, there are colonies with a special, incomparable shape $[3,4]$. The cultural characteristics of the yeast strains isolated on the basis of the cell morphology of the strains in the group of the genus Saccharomyces had distinctive features from the isolates allocated to the group of non-Saccharomyces. The cultural characteristics of the strains within the genus Saccharomyces also differed. The giant colonies had a diameter of 23-28 mm, a dense oily, smooth or wrinkled structure, with a smooth or wavy edge. On the contrary, yeast isolates of non-Saccharomyces. yeast had a larger diameter of 30-32 mm, a flat, smooth surface with or without partitions.

The study of the morphological properties of yeast isolates showed that the cells of most strains had a round, ovoid and oval shape characteristic of the genus Saccharomyces with the formation of asci with 1-4 smooth shiny spherical spores (Fig. 1a). For monocultures isolated on grapes of the Pervenets Magaracha variety, the proportion of the genus Saccharomyces yeast according to the morphological characteristics of the cells was $86.7 \%$, for the Krasnostop Anapsky variety - 80\% (Table 1). The yeast microflora also contained specimens whose morphological properties were characterized by the presence of rather small oval, elliptical, and lemon-shaped cells characteristic of "wild" yeast, the so-called nonSaccharomyces. (Fig. 1b). 


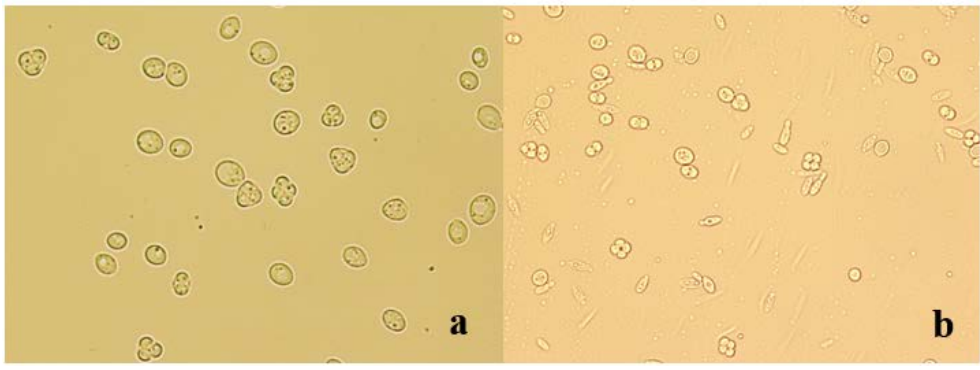

Note: yeast isolate cells: $a$-Saccharomyces; $b$ - non-Saccharomyces

Fig. 1. Morphological features of yeast isolate cells

Table 1. Morphological features of cell strains

\begin{tabular}{|c|c|c|}
\hline $\mathrm{C}_{\text {Samples }}^{\text {Cell morphology }}$ & $\begin{array}{l}\text { Spores are rounded, } \\
\text { orbicular, oval }\end{array}$ & $\begin{array}{l}\text { Lemon-like, } \\
\text { elliptical }\end{array}$ \\
\hline Krasnostop Anapsky & $\begin{array}{l}\text { Krt1- Krt5, Krt7, Krt9, } \\
\text { Krt11-Krt14, Krt17, Krt19- } \\
\text { Krt30 }\end{array}$ & $\begin{array}{l}\text { Krt6, Krt8, Krt10, Krt15, } \\
\text { Krt16, Krt18 }\end{array}$ \\
\hline Pervenets Magaracha & $\begin{array}{l}\text { PM1, PM2, PM4, PM6- } \\
\text { PM22, PM-24-PM28, } \\
\text { PM30 }\end{array}$ & PM3, PM5, PM23, PM29 \\
\hline
\end{tabular}

The morphological and cultural assessment does not allow to accurately determine the species belonging of strains due to the fact that the same strains may have different morphological and cultural characteristics. For an accurate determination, a genetic analysis is necessary. To identify the genus, primers rITS 1 / rITS 4 (Syntol) were used. Obtaining PCR reaction products with a size of $850 \mathrm{bp}$. indicates that the strain belongs to the genus Saccharomyces (fig. 2).

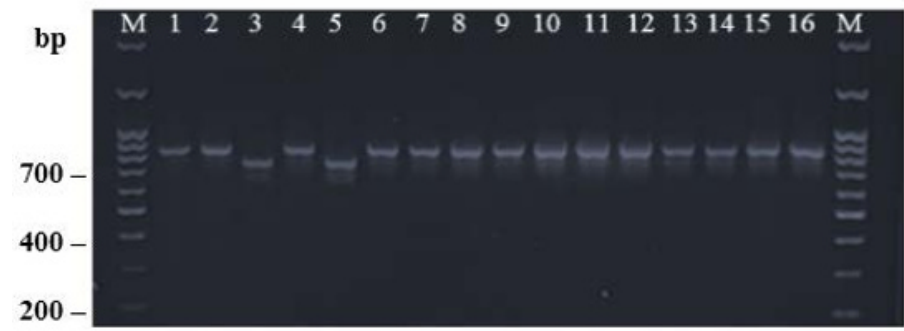

Note: M -100-kb molecular weight marker (Invitrogen);

1-16 - monocultures of yeast strains isolated on the Pervenets Magaracha variety

Fig. 2. Electroforetic pattern of rITS-PCR products from 16 different strains isolated by Pervenets Magaracha grape varieties

The next step was the type determining of yeast isolates by using specific primers rITS 1 / rITS 4 (Syntol) and restriction endonuclease HaeIII (SibEnzyme). Strains of autochthonous yeast № 1, 2, 4, 6 - 30 isolated on the grape white variety Pervenets Magaracha had PCR products in the form of four restriction enzyme fragments of rDNA: $325 \mathrm{bp}, 230 \mathrm{bp}, 170 \mathrm{bp}$, 125 bp, characteristic of the species S. cerevisiae / S. paradoxus. Strains № 3, № 5, № 23, № 29 had a PCR product of $750 \mathrm{bp}$, which is presumably characteristic of the species 
Hanseniaspora uvarum. Strains isolated on cultivar Krasnostop Anapskiy № 1-5, 7, 9, 1114, 17, 19-30 had PCR reaction products characteristic of the species S. cerevisiae / S. paradoxus. Strains № 6, 8, 10, 15, 16, 18 are presumably Hanseniaspora uvarum (fig. 3 ). The percentage of genus Saccharomyces isolated on the Pervenets Magaracha variety is $86.7 \%$, Krasnostop Anapskiy - 80\%.

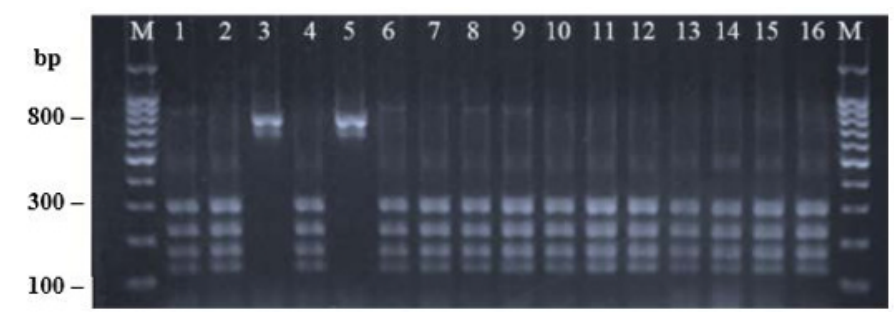

Note: M -100-kb molecular weight marker (Invitrogen);

1-16 - monocultures of yeast strains isolated on the Pervenets Magaracha variety

Fig. 3. Restriction patterns of 16 different strains isolated by Pervenets Magaracha grape varieties

As a result of our research, 60 pure cultures of local yeast were isolated and selected from the fermenting wort of white and red varieties. It was found that $83.3 \%$ of isolates belong to the species S. cerevisiae / S. paradoxus, $16.7 \%$ - non-Sacharomyces, presumably Hanseniaspora uvarum. The data obtained can be used for further evaluation of yeast isolates for a complex of wine-making characteristics and for isolating a strain that is promising for wine-making.

The reported study was funded by RFBR and Krasnodar Region according to the research project No. 20-316-90049 «Postgraduates»

\section{References}

1. https://msh.krasnodar.ru/deyatelnost/activities/vinagro/

2. A.J. Redagon, F. Perez, M.E. Valades et al., Food microbial. 14, 247-254 (1997).

3. C. P. Kurtzman, J. Piškur, Com. Gen.: Using Fungi as Models, 29-46 (2006).

4. J.A. Barnett, Microbiol. (Read., Engl.) 149 (3), 557-567 (2003).

5. H. Šuranská, D. Vránová, J. Omelková, R. Vadkertiová, Chemical Papers 66 (9), 861868 (2021).

6. T.N. Tanashchuk, M.Yu. Shalamitsky, M.V. Ermikhina, L.A. Mikheeva, Vit. and Win. 47, 48-51 (2018).

7. M. Tufariello, M. A. Chiriatti, F. Grieco, LWT-Food Science and Techn. 58, 35-48 (2014).

8. N.M. Ageeva, A.V.Ashes, A.I. Nasonov, I. I. Suprun, Fruit grow. and vitic. of the S. of Russia 52 (4), 110-122 (2018).

9. I.I. Suprun, N.M. Ageeva, E.V. Lobodina, A.I. Nasonov, S.V. Tokmakov, A.V. Prah, Fruit grow. and vitic. of the S. of Russia 59 (5), 118-132 (2019).

10. N. I. Bur'yan, Mikrobiol. vinodeliya, 433 (2002).

11. E.I. Kvasnikov, I.F. Shchelokova, Yeast, 320 (1991).

12. L. Granchi, M. Bosco, A. Messini, M. Vincenzini, J. Appl. Microbiol. 87, 949-956 (1999).

13. E.S. Magomedova, D.A. Abdullabekova, Sh. A. Abramov, S. of Russia: ec., develop. 1, 99-102 (2009). 